\title{
UM MÉTODO ENTRE A FILOSOFIA DA INFORMAÇÃO EA ORGANIZAÇÃO DO CONHECIMENTO: Wittgenstein, epistemologia histórica e crítica da linguagem
}

\author{
Gustavo Silva Saldanha*
}

RESUMO A partir do percurso metodológico de Wittgenstein, a presente reflexão filosófica discute as possibilidades de sistematização de um método filosófico, no contexto da filosofia da linguagem ordinária, que vai da filosofia da informação à organização do conhecimento. Os conceitos de gramática, linguagem ordinária, jogos de linguagem e apresentação panorâmica são discutidos como bases para uma relação entre "recordar" e "filosofar". Para o estudo, foram consultadas as fontes clássicas, em sua tradução para o português, do Tratado-Lógico-Filosófico e Investigações Filosóficas, com o cotejamento das traduções portuguesa e brasileira, além de fontes complementares, junto de diferentes comentadores, que indicam as mudanças de perfil do pensamento de um "primeiro" para um "segundo" Wittgenstein. O itinerário do método wittgensteiniano na direção do "solo áspero" nos permite reencontrar uma epistemologia histórica no contexto da formação do pensamento informacional, reestabelecendo um diálogo entre filosofia e epistemologia, epistemologia e teorias, dentro do campo, recontextualizando e reaproximando os cenários de produção conceitual, teórica e metodológica Ciência da Informação. Especificamente, no plano sociossimbólico, o método wittgensteinano nos recoloca diante de uma dimensão ampla e aberta para a crítica da cultura: sua visão "gramatical", sustentada pela linguagem, funda um modo de perceber a dinâmica das diferenças e suas identidades na realidade social, demandado o olhar permanente sobre as contingências e suas singularidades. Trata-se, pois, em última instância, de um método cultural para a filosofia da informação tecida a partir dos olhares da Ciência da Informação.

Palavras-chave: Filosofia da Informação. Epistemologia da Ciência da Informação. Ludwig Wittgenstein. Filosofia da Linguagem. Epistemologia histórica.

\footnotetext{
* Doutor em Ciência da Informação pela Universidade Federal do Rio de Janeiro, Brasil. Professor da Unversidade Federal do estado do Rio de Janeiro, Brasil. Docente permanente do Programa de Pós-Graduação em Ciência da Informação do convênio entre o Instituto Brasileiro de Informação em Ciência e Tecnologia e a Universidade Federal do Rio de Janeiro, Brasil.

E-mail: gustavosilvasaldanha@gmail.com.
}

\section{UMA INTRODUÇÃO À METODOLOGIA FILOSÓFICA WITTGENSTEINIANA NO CONTEXTO DA CIÊNCIA DA INFORMAÇÃO}

"One of Wittgenstein's methods in philosophy is to expose illusions lurking in our ordinary language that become full-blown when we come to reflect on the words we use." (FROHMANN, 1990, p. 87)

m contextos significativos da produção do conhecimento em filosofia da informação $\checkmark$ a partir das lentes do pensamento em Ciência da Informação (CI), Ludwig Wittgenstein se coloca como um interlocutor central para a reflexão filosófica do campo. Podemos 
pontuar a influência do filósofo nos estudos informacionais, por exemplo, no pensamento de Maria Nélida González de Gómez (1996), Rafael Capurro (1992, 2003), Birger Hjorland (2005), Blair (1992, 2003) e de Bernd Frohmann (2009, 1990). Em diferentes cenários, pois, o filósofo austríaco é reconhecido como central para uma crítica à substancialização e à essencialização do discurso sobre a informação dentro do campo. O desdobramento da reflexão filosófica de Wittgenstein, concentrado na linguagem, chega até questões centrais para uma crítica da organização do conhecimento, como veremos em Novellino $(1996,1998)$ e Hajibayova e Buente (2017) e, principalmente, em Frohmann (2009, 1990), que realiza este percurso completo, porém, de modo inverso, indo da crítica ao mentalismo da organização do conhecimento à filosofia da informação. Frohmann (1990) movimentase, pois, de maneira direta, sob a via da crítica wittgensteiniana, explorando de modo mais claro o método do filósofo de Viena.

Por trás desta influência, para além dos conceitos centrais do pensamento wittgensteiniano, se encontra um método filosófico que sugere possibilidades para a compreensão dos dilemas contemporâneos da informação, partindo do plano filosófico, atravessando o contexto epistemológico (da própria $\mathrm{CI}$ ) e chegando às teorias informações e suas potencialidades empíricas. Wittgenstein nos demonstra diferentes modos de percepção do real via a linguagem, indo da lógica à pragmática. Tal método terá influências, diretas ou indiretas, na própria constituição de teorias e de práticas no próprio campo informacional (SALDANHA, 2010; GRACIOSO, SALDANHA, 2011). Eis o foco central desta reflexão filosófica: analisar e discutir o potencial de sistematização do método wittgensteiniano como um modo de reconhecer e de problematizar a filosofia da informação no cerne da CI.

Apesar da influência formal de Wittgenstein no campo informacional, a sistematização de seu método ainda é ausente na produção filosófica da CI. Em outros termos, a apropriação wittgensteiniana tem se desenvolvido na literatura do campo, mas ainda ausente de um debate sobre os modos de definição de seus conceitos e de suas operacionalizações. Para desenvolvimento deste propósito, pois, recorremos à Filosofia da Linguagem. Nesta, encontramos o filósofo
Ludwig Wittgenstein e a tentativa de construção de um método próprio para a atividade filosófica. Esta tentativa se dá no contexto dos anos 1930, quando o filósofo vienense começa a desenvolver seu "olhar antropológico" sobre a linguagem. Neste âmbito, Wittgenstein prepara a obra máxima da segunda fase de seu pensamento, Investigações Filosóficas. Aparecem aqui diferentes textos não publicados pelo filósofo, apenas compilados por alunos, como o Livro Azul e o Livro Marrom, e editados após sua morte.

Como nos revela Condé (1998, p. 25), o chamado "primeiro Wittgenstein" trata a linguagem a partir de uma relação direta com o mundo - o espelhamento mundo/signo. Além disso, esta fase do pensamento do filósofo de Viena toma a ontologia, ou a estrutura da realidade, como um dado anterior à linguagem. A procura pelo estudo da linguagem resultaria na identificação de uma linguagem ideal. No espaço-tempo da formulação do segundo momento de sua reflexão, temporalmente delimitado pela produção textual elaborada e pelas aulas ministradas ao longo dos anos 1930, o pensamento wittgensteiniano procurará uma análise terapêutica dos estratos da linguagem, ou seja, uma possibilidade de tratar a linguagem como um médico, para evitar que ela, como uma doença, nos traga problemas.

Podemos identificar que a pergunta tradicional da filosofia - o seu "o que é" é substituída nesta outra fase pela questão "como", afirma já a interseção - fundamental para os estudos informacionais - entre filosofia e metodologia, ou, entre "filosofar" e "aprender a refletir filosoficamente". Deste modo, não indagamos, na filosofia pragmatista (ou da linguagem ordinária) wittgensteiniana, o que é a linguagem, mas como ela funciona. Não buscamos mais " $\mathrm{A}$ " linguagem (aqui já tomada como a tal "linguagem ordinária").

Para Wittgenstein, existem diferentes "linguagens" para aquém e além daquilo que tratamos como "lógica", o que permitirá ao filósofo austríaco estabelecer um dos conceitos mais importantes de toda sua filosofia: os jogos de linguagem. A filosofia investiga "uma variedade imensa de usos, uma pluralidade de funções ou papéis que poderíamos compreender como jogos de linguagens." (CONDÉ, 1998, p. 86) Em síntese, a concepção de "jogos de linguagem" nos permite determinar 
alguns pressupostos clássicos da filosofia wittgensteiniana, que tomam a significação a partir do uso dos termos na linguagem - ou, simplesmente, o significado como uso. Os "jogos de linguagem" têm como referência o contexto da vida social, e neste atuam. Descrever uma linguagem significa observar uma "forma de vida", a partir de sua "apresentação panorâmica".

O jogo de linguagem é uma parte, ou parte de uma atividade, de uma "forma de vida". As regras da "gramática" que rege esta forma de vida são também flexíveis, e se transformam junto das necessidades apresentadas na atuação dos indivíduos em cada comunidade, ou seja, uma "forma de vida". Será através da "gramática" que poderemos constituir critérios de racionalidade para nossa atuação.

Diante das indagações do filósofo de Viena, no plano procedimental, a proposta de tal reflexão filosófica é, pois, adentrar o pensamento metodológico de Wittgenstein em seu modo de constituição e de aplicação de um método filosófico, no contexto da filosofia da linguagem ordinária, indicando seus principais conceitos e abordagens. Para o estudo, foram consultadas as fontes clássicas, em sua tradução para o português, do Tratado-Lógico-Filosófico e Investigações Filosóficas (WITTGENSTEIN, 2002, 1979, 1968), com o cotejamento das traduções portuguesa e brasileira, além de fontes complementares, junto de diferentes comentadores, que indicam as mudanças de perfil do pensamento de um "primeiro" para um "segundo" Wittgenstein. Adotamos, ainda, para a revisão conceitual, a exploração lexical realizada por Glock (1998).

Acreditamos que a reflexão contribui para a compreensão da profundidade do pensamento epistemológico do filósofo vienense, principalmente em sua distinção metodológica com a obra de Karl Popper, como estudado em Edmonds \& Eidinow (2003). Do mesmo modo, a proposta, projetamos, permite revisitar a conceitualidade wittgensteiniana à busca da correlação entre conceito e método, permitindonos "ver" o filósofo em seu ato reflexivo de criação. Enfim, o estudo nos permite identificar os potenciais de compreensão de um método que descortina a epistemologia histórica do campo, a partir da crítica à linguagem, chegando até um olhar sobre a cultura como centralidade filosófica informacional.

\section{RECONHECENDO UM MÉTODO EM FILOSOFIA: a "apresentação panorâmica" Darstellung) em Wittgenstein}

“[...] os aspectos para nós mais importantes das coisas estão ocultos pela sua simplicidade e trivialidade. (Podemos não notá-los por tê-los sempre diante dos nossos olhos)." (WITTGENSTEIN, 1979, p. 34).

Os anos 1930 redefinem a filosofia de Wittgenstein sobre alguns aspectos fundamentais. Dentre eles, destacamos: mudança na forma de encarar a linguagem; mudança na maneira de conceber o fazer filosófico. No caso do primeiro tópico, identificamos uma caminhada que abandona a lógica em prol da pragmática para refletir sobre o papel da linguagem no pensamento. No segundo caso, aquele que mais nos importa aqui, o filósofo austríaco concebe uma nova forma de construir um pensamento. Em outras palavras, temos aqui o desenvolvimento de um método para a leitura filosófica do mundo.

Ao longo da década de 1930, Wittgenstein alimenta um conjunto de papéis, pessoalmente, e, indiretamente, multiplica suas anotações a partir das notas dos alunos que receberam suas aulas. Dentre as obras que se destacam como "fases de construção" das "Investigações Filosóficas", estão o Livro Azul, o Livro Marrom e Big Typescript. São obras que demarcam uma grande mudança na trajetória do pensamento do filósofo vienense, tanto no escopo teórico, quanto metodológico. (MORENO, 2000, JANIK, A.; TOUMIN, 1991; HALLER, 1990, TUGENDHAT, 1992, MONK, 1995)

Aplicada ao discurso em sua teatralização - seu uso -, podemos afirmar que a alma do signo é seu uso - "[...] se tivéssemos de mencionar o que anima o signo, diríamos que é a sua utilização" (WITTGENSTEIN, 1992a, p. 30). Assim como no teatro, mais que a representar, atuar não é apenas figurar, o que conduz/provoca a interpretação de sentido; a atuação é, em si, a própria interpretação - o filósofo, assim, "abandona a racionalidade contemplativa do ver (sehen), presente no paradigma da representação, para adotar uma racionalidade que se constitui a partir da nossa 
gramática e do nosso atuar (hondeln)" (CONDÉ, 2001, p. 169).

$\mathrm{O}$ conceito de "sistema linguístico" que ajuda a tecer a ideia da multiplicidade de "jogos de linguagem" e a constituir a noção de "forma de vida" é aquele lugar onde o signo obtém seu significado. Ou seja, "numa palavra: compreender uma frase significa compreender uma linguagem". Isto nos permite afirmar que "a frase tem vida, pode dizer-se, enquanto parte integrante do sistema de linguagem." (WITTGENSTEIN, 1992a, p. 31)

No Livro Azul, Wittgenstein apresenta o conceito de "jogos de linguagem". A partir dele, podemos compreender outras noções fundamentais, aqui metodologicamente abordadas, a saber: semelhanças de família, gramática, formas de vida, vivência, uso. Como sintetiza Moreno (2000), quando nos perguntamos o que é a linguagem sob essa via interpretativa, dizemos: são os jogos e suas semelhanças.

A elaboração do significado de jogos de linguagem, tecida junto à ideia de definições ostensivas, nos permite uma dupla aplicação enquanto método no presente estudo, tendo papel preponderante para a investigação que se propõe: de um lado, o conceito é tomado como ensino, de outro, como ferramenta/instrumento de aprendizagem, que se estabiliza enquanto regra.

Se o sentido da palavra amarelo nos for
ensinado por recurso a uma qualquer
espécie de definição ostensiva (uma
regra para o uso da palavra) este
ensino pode ser considerado de duas
maneiras diferentes: A. o ensino é
uma repetição. Esta repetição leva-
nos a associar uma imagem amarela,
coisas amarelas, com a palavra amarelo.
[...]. B. O ensino pode ter-nos
proporcionado uma regra que
está envolvida nos processos de
compreensão, execução de uma
ordem, etc.; envolvida significando,
contudo, que a expressão desta
regra faz parte destes processos.
(WITTGENSTEIN, 1992a, p. 40, grifo
nosso).

De fato, por jogos de linguagem podemos conceber mais que um conceito-ferramenta, mas também uma metaferramenta conceitual, um instrumento para compreender conceitos. Wittgenstein (1992a) adotará o conceito como um elemento instrumental para seu próprio esclarecimento sobre filosofia. A noção de jogos de linguagem aparece assim, no ato da prática docente do filósofo de Viena, como um recurso para o pensamento e para a exteriorização.

\begin{abstract}
De futuro, chamarei muitas vezes a vossa atenção para aquilo que chamarei jogos de linguagem. Estes são maneiras mais simples de usar signos do que as da nossa linguagem altamente complicada todos os dias. Os jogos de linguagem são formas de linguagem com que a criança começa a fazer uso das palavras. $O$ estudo dos jogos de linguagem é o estudo de formas primitivas da linguagem ou de linguagens primitivas. Se pretendemos estudar os problemas de verdade e da falsidade, de acordo e desacordo de preposições com a realidade, da natureza de asserção, da suposição e da interrogação, teremos toda a vantagem em examinar as formas primitivas de linguagem em que estas formas de pensamento surgem, sem $\circ$ pano de fundo perturbador de processos de pensamento muito complicados. Quando examinamos estas formas simples de linguagem, a névoa mental que parece encobrir o uso habitual da linguagem desaparece. Descobrimos atividades, reações, que são nítidas e transparentes. Por outro lado, reconhecemos, nestes processos simples, formas de linguagem que não diferem essencialmente das nossas formas mais complicadas. Apercebemonos da possibilidade de construir as formas complicadas pela adição gradual de novas formas a partir das formas primitivas. (WITTGENSTEIN, 1992a, p. 47, grifo nosso)
\end{abstract}

A longa citação permite-nos apreender como Ludwig Wittgenstein (1992a) começa a elaborar, no âmbito da prática de ensino/ reflexão da filosofia, um conceito que é, em si, uma ferramenta didática para a filosofia. O que o filósofo nos convoca aqui é para constituição de uma nova maneira de pensar, de fazer e de ensinar filosofia. Podemos, através de jogos de linguagem, conceber problemas filosóficos como questões cotidianas passíveis de resoluções, e não problemas mentais privados ou externos, que se distanciam dos dias dos homens.

A forma como a criança aprende - como inicia o uso/jogo das palavras - é um índice 
referencial para percebermos como se dá o processo de aprendizagem e de resolução dos problemas do mundo. Através de recursos simples, munidos de poucas ou raras palavras, crianças conseguem solucionar inúmeros problemas de seu cotidiano usando a linguagem. Investigar os jogos de linguagem de cada comunidade é reconhecer suas formas primitivas, ou ainda, sua própria linguagem primitiva - os primeiros conceitos, as primeiras significações dos primeiros conceitos, ou, apenas, os primeiros usos dos quais se multiplicaram os usos futuros.

O conceito em construção em Wittgenstein no início dos anos 1930 serve também para esclarecer a crítica que o filósofo faz à filosofia clássica. Para ele, o desejo de uma generalidade universal atravancou o desenvolvimento filosófico. As principais "confusões filosóficas particulares" derivariam desta procura pelo absoluto - ou, já no vocabulário da filosofia da linguagem ordinária wittgensteiniana, a busca por algo que fosse uma identidade comum a todos os jogos de linguagem disponíveis ou em elaboração no mundo terminou por encarcerar o filósofo em uma única luz.

A investigação pelo elemento "consanguíneo" em todos os jogos - o parentesco ancestral de toda a linguagem - terminou por estabelecer uma forma de estudo/aprendizagem da palavra como imagem - figuração -, reduzindo as leis naturais ao menor número. Ao contrário desta tentativa, o filósofo conduz a filosofia a outra linha de compreensão - "a filosofia é meramente descritiva" (WITTGENSTEIN, 1992a, p. 47), afirma no Livro Azul.

Podemos recuperar, na mesma obra, aquilo que é contextual em nossa proposta: o método filosófico wittgensteiniano. Este método está no reconhecimento da linguagem ordinária como uma linguagem "perfeita". Esta "perfeição" não aponta para uma superestrutura metafísica. Ao contrário, ela está no lugar do solo áspero, onde conseguimos, com as ferramentas linguísticas disponíveis, como a criança, solucionar nossas questões cotidianas - estas, sim, "universais". O pragmatismo wittgensteiniano nos convida a perceber o universal no local - "todos os fatos que nos interessam encontram-se expostos perante nós". (WITTGENSTEIN, 1992a, p. 32).

Para o filósofo,

É um erro afirmar que em filosofia consideramos uma linguagem ideal em contraste com a nossa linguagem comum. Isto poderia levar-nos a crer que podíamos fazer coisa melhor que a linguagem comum. Mas a linguagem comum é perfeita. Sempre que produzimos linguagens ideais não - fazemos para substituir a nossa linguagem comum por elas, mas apenas para eliminar alguns problemas que decorrem do facto de alguém pensar que entrou na posse do uso exacto de uma palavra vulgar. É também por esse motivo que o nosso método não consiste apenas na enumeração de usos efectivos de palavras, mas antes na invenção deliberada de novos usos, alguns dos quais por causa da sua aparência absurda. (WITTGENSTEIN, 1992a, p. 62, grifo nosso)

Através do recurso filosófico-didático dos jogos de linguagem, debruçado sobre a linguagem que comungamos no cotidiano, o filósofo procura colecionar usos de palavras e construir outros usos, a partir da revisão da atuação das palavras. Este é seu método. Um método simples, afirma o olhar wittgensteiniano, que se pauta na observação daquilo que está diante de nossos olhos. A "criação de novos usos" na verdade não se trata de uma invenção originária. Ao contrário, provém da hibridização dos usos - a complexa relação que se dá entre jogos de linguagem provoca novos usos para velhos signos.

Podemos imaginar, deste modo, aquilo que não existe. Imaginamos, no entanto, a partir de aproximações entre tudo aquilo que é existente - e o é em nosso convívio - "como se pode imaginar o que não existe? A resposta parece ser: se o fazemos, imaginamos combinações não existentes de elementos existentes. Um centauro não existe, mas a cabeça, o tronco e os braços de um homem e as patas de um cavalo existem." (WITTGENSTEIN, 1992a, p. 66)

No Livro Marrom, o filósofo de Viena complementa a compreensão dos limites e "deslimites" da noção de "jogos de linguagem". Estes não são "partes incompletas de uma linguagem". Para a filosofia da linguagem ordinária wittgensteiniana, estes jogos representam linguagens completas em si mesmas - ou seja, temos aqui a afirmação do universal no contextual. Nas palavras do filósofo, eles representam "sistemas completos da comunicação humana. Para manter o presente ponto de vista é, muitas vezes, útil imaginar essa linguagem simples como constituindo o sistema completo de 
comunicação de uma tribo, num estádio primitivo da sociedade. Pensem na aritmética dessas tribos." (WITTGENSTEIN, 1992b, p. 14).

Um jogo é ilustrado pelo filósofo de Viena para demonstrar como se dá nossa apreensão do mundo através dos jogos de linguagem. Tendo, por exemplo, uma lista de palavras, parte delas familiares, outra parte desconhecida - sem sentido -, chamamos as primeiras de primitivas. É a partir de um exercício de sim e não sobre o significado dos termos, e de aproximações aos significados, a partir dos usos conhecidos das palavras primitivas, que chegamos às cercanias da significação de um termo. É esta experiência, que se dá na atuação do discurso, que Wittgenstein chamará "experiência de compreender." (WITTGENSTEIN, 1992b, p. 101). Como visto, não se trata de uma experiência de definição, mas de aproximação; não há aqui a afirmação da verdade do sentindo de algo, mas de suas margens de verossimilhança.

A técnica de usar conexões resulta em outra importante construção conceitual wittgensteiniana, claramente desenvolvida no Livro Marrom. Com algumas palavras, sentimos imediatamente uma certa "sensação de familiaridade"; com outras, não. Para estes últimos, procuramos possíveis conexões - laços - de proximidade, para tentar compreender as primeiras, tratadas, como visto, como primitivas. Segundo o filósofo, "há um grande número de experiências, algumas das quais, sensações, a que poderíamos chamar experiências (sensações) de familiaridade" (WITTGENSTEIN, 1992b, p. 130).

Estas semelhanças representam, como lembra Condé (1998, p. 93), uma estrutura flexível, definida como "traços mutáveis", que permitem a permanente reconfiguração do reconhecimento dos significados. Podemos ainda observar que as semelhanças de família são, na verdade, "as semelhanças entre aspectos pertencentes aos diversos elementos que estão sendo comparados, mas de forma tal que os aspectos semelhantes se distribuem ao acaso por esses elementos. Esses aspectos semelhantes se entrecruzam aleatoriamente, sem repetir-se uniformemente". (CONDÉ, 2001, p. 50-51)

O "datiloscrito" de 1933, conhecido como Big Typescript, é um exemplo do pensamento wittgensteiniano que concebe a "apresentação panorâmica" a partir de uma rede de significados. O texto reúne as novas concepções de Wittgenstein, principalmente em relação à sua noção de gramática. No discurso apresentado, o filósofo vienense procura relacionar o livro - o texto - ao espírito daquele que o concebe. Assim, Wittgenstein desenvolve uma maneira original de escrever, junto da originalidade do pensamento que precede a escrita. É conferido lugar à escrita como um ritual de redação diária, tendo por horizonte o livro que expressa o pensamento do filósofo. (ALMEIDA, 2008)

Ao final da redação do texto datilografado, Wittgenstein não se satisfaria. A partir de então o ritual da escrita é desdobrado com anotações sobrepostas, manuscritas, sobre o texto datilografado. É neste momento, segundo algumas visões, que emerge o novo método. Do livro ao álbum, esta é a passagem do pensamento de Wittgenstein sobre o método filosófico da essência para as linguagens. O álbum, diferentemente do livro, representa o complexo da atitude diária de anotações, um ritual de escritura que vai registrando o pensamento em sua gestação, aproximandose mais da mente do que da mão do filósofo. "O álbum, que não se confunde com a letra do texto, realiza o espírito prometido pelo prefácio do livro, e se apresenta, assim, como porta de entrada para a forma de vida do autor." (ALMEIDA, 2008)

A principal preocupação do método, compreendido como uma gramática, é a construção de uma terapia que permita o afastamento das confusões conceituais. Sua função está no desenvolvimento de descrições da linguagem, sendo simultaneamente transformador e não dogmático. Enquanto seu método anterior se desenvolvia através da demonstração, provas e evidências, baseando-se nas ciências naturais e na lógica, o novo método não se orienta pelos conceitos científicos, mas por um procedimento terapêutico. (ALMEIDA, 2008)

Neste momento, Wittgenstein concebe o conceito de "apresentação panorâmica". Segundo Almeida (2008, p. 6), este novo tecido conceitual pode ser identificado por sua relevância por demarcar a nossa forma de apresentação e a maneira como vemos as coisas; por proporcionar a compreensão e tomar esta como possibilidade de "ver as concatenações", além de decorrer daí a importância de encontrar "elos intermediários". É esta a possibilidade de interpretar a filosofia a partir de uma apresentação que orienta nossa argumentação.

O Big Typescript foi organizado em 1933. Seus escritos derivam de manifestações 
registradas do pensamento do filósofo austríaco entre 1930 e 1932. Segundo Luckhart (1991), neste momento, Wittgenstein se propõe a debater estruturalmente duas questões: o que a filosofia é e o que ela deveria ser. O filósofo argumenta, de forma dura, contra a filosofia tradicional, principalmente sua pretensão de universalidade. Como já mencionamos, a própria natureza da filosofia é aqui criticada, avaliada, reelaborada. E a partir desta releitura do papel da filosofia na vida dos homens, Wittgenstein afirma ter descoberto um novo método, capaz de "curar" estes homens de seus problemas filosóficos.

No Big Typescript, Wittgenstein condena a divisão clássica da filosofia sobre os objetos essenciais e os objetos acidentais. Para o filósofo, esta diferença é desnecessária - como também representa um erro. O olhar wittgensteiniano oferece aqui uma aproximação aos problemas renunciados - negligenciados - historicamente pela filosofia daqueles colocados não apenas como fundamentais, mas, também, como únicos. Neste sentido, Wittgenstein retira da filosofia sua "soberba", mas, ao mesmo tempo, concede uma certa "nobreza" aos problemas tratados como insignificantes, não essenciais, como aqueles do cotidiano. Não existe, pois, problemas totalmente superiores, como também não existem aqueles entraves absolutamente simples. (LUCKHART, 1991)

Quando nos pegamos em determinados problemas - essenciais, não essenciais -, estamos diante de uma questão filosófica que nos trava não por sua transcendentalidade, mas por sua "gramática". Nosso pensamento está enraizado em uma gramática - em um vocabulário e sua articulação peculiar - que nos impede de escapar. A filosofia, por isto, trabalha com recordações. Mas não a recordação do mundo inteligível de Platão, mas aquele complexo labiríntico de lembranças da gramática que é aprendida, pelo hábito, ao longo de nossa formação. Trazer as palavras do seu uso metafísico para o uso cotidiano torna-se, então, uma função do filósofo. Isto demarca a filosofia como uma terapia - e, mais do que isto, o modo de fazer filosofia, seu método, como um processo de cura. A principal dificuldade, para Wittgenstein, no estudo da filosofia, está em delimitar uma regra. Se conseguimos delimitar uma regra que nos ajuda, os problemas começam a ser diluídos. (LUCKHART, 1991)

Estabelecer ou recordar uma regra, trazer as palavras para seu uso cotidiano, comparar usos de palavras, tomar os múltiplos significados de uma só palavra, tudo isso permite à terapia que é a filosofia resolver nossos problemas. Em outras vezes, é necessário descobrir o que o filósofo chamará de "palavra libertadora" (das erlosende Wort). É este tipo de palavra que permite compreender o que, até então, havia pesado a consciência. A palavra que consegue, de fato, expressar o problema, torna o problema inofensivo. Uma vez encontrada a palavra libertadora, usá-la para afastar os problemas é bastante simples. A palavra libertadora é comparada pelo filósofo ao bloqueio e desbloqueio de cofres. Um determinado código - alfabético, numérico ou alfanumérico - se apresenta. Nenhuma força pode abrir o cofre, mas uma palavra o pode. (LUCKHART, 1991, p. 268)

Por fim, também colaborará diretamente para a cura dos problemas filosóficos a recorrente lembrança da gramática constituída no tempo. Ao filósofo, cabe montar, organizar e manifestar bilhetes para uma finalidade específica. $\mathrm{O}$ caráter terapêutico está em saber recordar e saber organizar as recordações. Mas a filosofia e o fazer filosófico estão além deste caráter terapêutico. Em primeiro lugar, a filosofia atua como força preventiva e tem um papel crítico e corretivo. A linguagem enfeitiça, por isso o filósofo deve cuidar de desmistificar as falsidades provocadas pelas representações. Em segundo lugar, a filosofia pressupõe um método. Seu valor não utilitário está aí.

No capítulo Filosofia, do Big Typescript, Wittgenstein trata do método da filosofia: a representação perspícua da gramática-linguísticafatos. A meta é a transparência dos argumentos, ou seja, justiça. O filósofo deve corrigir a injustiça da filosofia, deve ser justo com os termos, corrigindo-os, e não multiplicando seus credos. (LUCKHART, 1991). O discurso, como veremos a seguir, perpassa a construção de outros momentos da produção (auto)metodológica wittgensteinina. (WITTGENSTEIN, 2005, 1979)

Percebemos como, nos textos germinais do clássico da segunda fase do pensamento de Wittgenstein, as Investigações Filosóficas, o filósofo de Viena substitui a ontologia pela crítica da linguagem, colocando o discurso como prioridade na reflexão filosófica em relação ao ser. Desta maneira, importam mais ao "ontológico wittgensteiniano" as experiências impressas nos atos - que se desdobram em conceitos - dos indivíduos que vivenciam uma 
forma de vida, que a tentativa de afirmação do ser - o "é". Através do Livro Marrom, do Livro Azul e do Big Typescript, o filósofo concebe um método para a filosofia que nos permite compreender a ciência, por exemplo, como um feito conceitual dos homens, e, a partir destes fragmentos da linguagem, reconhecer sua gramática fundacional, viva em sua permanência na comunidade científica que se desenvolve.

\section{FILOSOFAR É RECORDAR: um percurso filosófico-terapêutico}

\begin{abstract}
"Não há um método da filosofia, mas sim métodos, como que diferentes terapias." (WITTGENSTEIN, 1979, p. 58)
\end{abstract}

Compreender uma palavra, isto é, aproximar-se de seu significado, são ações que se dão dentro de um sistema de linguagem. É visualizando este sistema, onde os signos podem ser apresentados como passíveis de significação, que o filósofo de Viena reorienta sua noção de lógica. Há que se perguntar pelo uso das palavras para tecer a aproximação, que pode ser elaborada pela sua descrição. Assim, antes de um espelho, o sentido de uma pergunta é "o método de responder a essa pergunta". O método no pensamento wittgensteiniano, voltado para uma "apresentação panorâmica" se desenvolve. Se, em um dado momento, nos questionávamos sobre o método para chegar às respostas, a filosofia da linguagem ordinária do filósofo de Viena nos apresenta um método para realizar perguntas. Perguntar pelo uso, partindo da descrição, é uma das sugestões mais importantes desta abordagem. $\mathrm{O}$ método pode estabelecer, ao final, o próprio sentido.

O verbo "ser" não é mais aquele que se apresenta como prioridade metodológica para a filosofia, como classicamente se deu. O pensamento filosófico se pautou, desde Sócrates, a usar a seguinte indagação: o que é? A partir desta, tenderíamos a chegar ao espelho da natureza, compreendendo o "ser" de cada coisa. Aqui nos perguntamos pela procura, pelo "como", anterior à preocupação com o "o que é". "Como" este ou aquele indivíduo pergunta/ age para resolver seus problemas? Nas palavras do filósofo, "diga-me como você procura e lhe direi o que você procura" (WITTGENSTEIN,
2005, p. 50). O próprio filosofar é um método de ensino/aprendizagem de nossa experiência de apresentação/interpretação do mundo.

Nas Observações Filosóficas, encontramos a afirmação de um método para a filosofia que não só está em fase de construção, como é a face de uma construção permanente. A filosofia é parte desta construção inacabada, posto que é diária. O próprio método o filósofo utilizará ao longo da década de 1930 para construir as Investigações Filosóficas posto que o método é a possibilidade filosófica já que permite aproximar os significados dos instrumentos que nos ajudam a agir no mundo, ou seja, os conceitos. Só podemos, afirma o filósofo austríaco, "indicar o comprimento de um objeto se disponho de um método para encontrar o objeto." (WITTGENSTEIN, 2005, p. 56)

E é este complexo sistema de linguagem, munido de suas regras, aquele que constituirá os limites de nossa compreensão, posto que demarca a gramática. Somos livres, mas dentro de fronteiras de linguagem. Não podemos conhecer o mundo que há fora de nossas possibilidades de nossa língua. "A gramática proporciona à linguagem os graus necessários de liberdade" (WITTGENSTEIN, 2005, p. 57). Um dos erros da filosofia é procurar uma espécie de compreensão, segundo a leitura wittgensteiniana, que está além de nossa linguagem. Isto, em sua visão, é impossível. Uma determinada "naturalidade do mundo" está, justamente, no "fato de que a linguagem pode referir-se, e de fato se refere, somente a ele". Isto se dá, esclarece o filósofo de Viena, porque a "linguagem só obtém sua forma de significar daquilo que significa, do mundo, portanto, não é concebível nenhuma linguagem que não represente este mundo." (WITTGENSTEIN, 2005, p. 65)

Também a filosofia está inserida na gramática, e não fora dela. Desta maneira, só pensamos o mundo a partir das possibilidades constituídas pela nossa expectativa que já respeita um modelo de referências concebido no âmbito da linguagem, e não da natureza. O filósofo de Viena apresenta, nas Observações Filosóficas, deste modo, uma visão peculiar de filosofia e do método filosófico, aproximando-a da ideia de recordação, porém de maneira diferente daquela instituída pela teoria da reminiscência platônica. Temos nesta virada do pensamento wittgensteiniano "a filosofia como depositária da gramática". Esta filosofia pode compreender a natureza 
do mundo, desde que reconheçamos que esta natureza não está aquém nem além da linguagem, mas na trama da própria linguagem - ou, ainda, "nas proposições da linguagem" e nas "regras para essa linguagem que excluam combinações de signos que resultem em contra-sensos" (WITTGENSTEIN, 2005, p. 69). Desta maneira, a filosofia é uma espécie de colecionadora de observações sobre o mundo que permitem aproximações aos seus significados - a "filosofia está constantemente recolhendo uma abundância de proposições sem se importar com sua verdade ou falsidade". (WITTGENSTEIN, 2005, p. 75)

Apresentados como instrumentos que ajudam o filósofo a construir um novo olhar sobre seu próprio pensamento filosófico, conceitos como "jogos de linguagem", "semelhanças de família", "gramática", "forma de vida" comporão a obra que marca a segunda fase wittgensteiniana, produzida ao longo da década de 1930, as Investigações Filosóficas. Temos aqui recuperados e desenvolvidos estes conceitos. A chamada "linguagem primitiva" é esclarecida como uma espécie de jogo de linguagem - um jogo que permite o desenvolvimento de outros jogos. Por sua vez, o plural conceito "jogos de linguagem" é reconhecido como "o conjunto da linguagem e das atividades com as quais está interligada". (§ 7, WITTGENSTEIN, 1979, p. 12)

Apesar de pensarmos a priori "presos" pela linguagem, não significa que estamos tomados por um processo de repetição. Muito pelo contrário, o conceito de "jogos", como visto, é plural e permite a multiplicação das possibilidades de regra a partir das regras iniciais comungadas - o método desconstrói o próprio método para criar novos objetos. A metáfora da "velha cidade" apresentada pelo filósofo de Viena é esclarecedora neste sentido. A linguagem nada mais é do que uma "rede de ruelas e praças, casas novas e velhas, e casas construídas em diferentes épocas; e isto tudo cercado por uma quantidade de novos subúrbios com ruas retas e regulares e com casas uniformes." (§ 18, WITTGENSTEIN, 1979 , p. 15). A cada dia, surge um novo conceito de uma velha regra de um velho jogo. Às vezes nos esquecemos que estamos jogando um velho jogo, porém com um conjunto de novas regras e novos instrumentos. Às vezes, nos esquecemos que estamos jogando um velho jogo, que foi completamente transfigurado, para adequar-se aos novos conceitos.

\section{JOGOS DE APRENDIZAGEM SOB GRAMÁTICAS PANORÂMICAS}

\author{
O trabalho do filósofo é um acumular \\ de recordações para uma finalidade \\ determinada” (§ 127, WITTGENSTEIN, \\ 1979, p. 57).
}

O que nos permite compreender uma palavra - um nome - é o apoio oferecido pela regra. O ensino volta a se afirmar na filosofia pragmatista wittgensteiniana no mesmo processo da compreensão filosófica - "a regra pode ser um auxílio do jogo". No entanto, antes de ensinada, esta regra, muita das vezes, é observada ou, ainda, apenas aplicada. Ela é "comunicada àquele que aprende e sua aplicação é exercitada. $\mathrm{Ou}$ é uma ferramenta do próprio jogo. Ou: uma regra não encontra emprego nem no ensino nem no próprio jogo, nem está indicada num catálogo de regras. Aprende-se o jogo observando como os outros o jogam" (§ 54, WITTGENSTEIN, 1979, p. 34). Apesar dessa oscilação no uso e na própria conceituação da ideia de regra, dizemos que aquele indivíduo aprendeu a regra, uma vez que se integrou à práxis do jogo - e jogou.

Ao jogar - e, simultaneamente, aprender a jogar - estamos exercitando aproximações a outros jogos já vivenciados em nosso cotidiano, ou em nossos sistemas de linguagens. Segundo o vocabulário wittgensteiniano, estamos a identificar "semelhanças, parentescos", na verdade, "toda uma série" de vínculos comuns - que não são identidades - que nos permitem jogar o jogo. É neste momento que o filósofo de Viena convoca uma apresentação panorâmica como método filosófico em uma só afirmação: "não pense, veja!" (§ 66, WITTGENSTEIN, 1979, p. 38)

Dessas aproximações entre jogos provém o importante conceito imerso do olhar pragmatista do filósofo - "não posso caracterizar melhor essas semelhanças do que com a expressão semelhanças de família" (§ 67, WITTGENSTEIN, 1979, p. 39). Saber jogar - ou "saber o que é um jogo" está pautado na possibilidade de descrição - de aproximação, e não de definição - de diferentes tipos de jogos. O conceito metodológico dos jogos de linguagem representa, na verdade, "objetos de comparação" que, "através de semelhanças e dissemelhanças, devem lançar luz sobre as relações de nossa linguagem" ( $\$$ 130, WITTGENSTEIN, 
1979, p. 57). Desta maneira, conclui o filósofo de Viena, "mostro que se pode construir, por analogia, todas as espécies possíveis de jogos; digo que quase não chamaria mais de jogo a isto, e assim por diante." (§ 75, WITTGENSTEIN, 1979, p. 42-43). É relevante notar a observação de Condé (2001) acerca da movimentação das semelhanças de família: "as semelhanças de família podem variar dentro de um determinado jogo de linguagem ou ainda de um jogo de linguagem por outro, isto é, essas semelhanças de família podem aparecer ou desaparecer na passagem de um jogo por outro" (CONDÉ, 2001, p. 51). Deste modo, encontramos semelhanças intermitentes, que podem ir e vir, conforme o contexto de análise - de terapia - de um dado conceito, ou de uma forma de vida como um todo.

Aprender/usar um significado é reconhecer, na verdade, uma "família de significação" (§ 77, WITTGENSTEIN, 1979, p. 43). E isto não se dá apenas com a mais vulgar - a mais ordinária - das linguagens, mas em todas. A linguagem científica também está diariamente subjugada pela oscilação da significância na vivência do signo, ou, nas palavras do filósofo, "a flutuação de definições científicas", que permite afirmar que, aquilo "que vale hoje, por experiência, como fenômeno concomitante do fenômeno A será utilizado amanhã nas definições de A" (§ 79, WITTGENSTEIN, 1979, p. $45)$, sem que tenhamos uma precisa ideia do que "naturalmente" - por natureza - seja A.

$\mathrm{O}$ que permanentemente o trabalho filosófico proposto pelo segundo Wittgenstein realiza está expresso no aforismo 119: “Nós reconduzimos as palavras do seu emprego metafísico para seu emprego cotidiano" (§ 119, WITTGENSTEIN, 1979, p. 55). Assim, todas as vezes que, neste momento, o filósofo trata da linguagem, ele refere-se à chamada linguagem do cotidiano. Esta parece simples e, ao mesmo tempo, trivial e inútil. No entanto, é ela a "linguagem primitiva" que permite a construção de qualquer conceito.

Nossa principal dificuldade na filosofia está, desta maneira, em reconhecer um método absolutamente diferente de fazer filosofia, ou seja, esquecemos de reconhecer uma visão panorâmica da linguagem. Este "caráter panorâmico" - Ueberschtlichkeit, expressão que em alemão também significará clareza - da linguagem permite--nos ver menos a representação, e mais as conexões. Como afirma o filósofo, "falta o caráter panorâmico à nossa gramática. A representação panorâmica permite a compreensão justamente em ver as conexões. Daí a importância de encontrar e/ou inventar articulações intermediárias" (§ 122, WITTGENSTEIN, 1979, p. 56, grifo nosso).

Há que se perceber que, em filosofia, segundo o pragmatismo wittgensteiniano, podemos muito, mas o fazemos sempre dentro da linguagem. Desta forma, o filósofo retoma sua consideração sobre a filosofia como uma "recordação". Não a "recordação" de um passado extrassensível. Ao contrário, a "recordação" que cuida de guardar, organizar e colocar em ação, no dia a dia, os jogos de linguagem que colaboram para nossa compreensão das palavras. Este é o "trabalho do filósofo", isto é, "um acumular de recordações para uma finalidade determinada" ( $\$ 127$, WITTGENSTEIN, 1979, p. 57). Diferentemente do filósofo em Platão, aquele que se dá no segundo Wittgenstein recorda não a ideia pré-concebida no mundo inteligível, mas, sim, lembra- -se dos signos pós-construídos no mundo da linguagem.

Em pouco tempo, estas espécies de signos a posteriori, que são coletivamente desenvolvidos na dinâmica dos jogos de linguagem, são apreendidos no lance de sua aplicação - e não mais refletidos. Não paramos para analisar por que dizemos se há ou não uma cadeira no ambiente em que estamos - simplesmente dizemos. A filosofia cuida, desta maneira, enquanto "colecionadora de recordações", de nos lembrar: veja, aqui está a cadeira. Isto é necessário, pois, à medida que se tornam comuns, deixamos de atentar para nossas construções, para nossas regras e os jogos que podem ser jogados dentro delas. Não nos perguntamos diariamente sobre o trivial uso que fazemos de nossas mãos; costumamos lembrar deste fato apenas quando temos uma das mãos indisponível por algum acidente. Aí lembramos: como me faz falta o uso trivial da mão.

Assim, "os aspectos para nós mais importantes das coisas estão ocultos pela sua simplicidade e trivialidade. (Podemos não notálos por tê-los sempre diante dos nossos olhos). A "recordação" da filosofia é, desta maneira, uma capacidade de demonstrar, diariamente, que o "o que é" das coisas é apenas "como estão" as coisas diante dos nossos olhos, de mostrar o que está em 
nosso próprio ambiente que, de tão frequentado, torna-se declaradamente invisível - "ninguém dirá que, cada vez em que entro em meu quarto, no meu ambiente habitual, ocorre um reconhecimento de tudo aquilo que vejo e vi centenas de vezes" (§ 603, WITTGENSTEIN, 1979, p. 158). Lembrar das nossas mãos antes que o acidente o faça pode indicar uma tarefa da filosofia. Assim, o "filósofo trata uma questão como uma doença" (§ 255, WITTGENSTEIN, 1979, p. 97), pois a linguagem pode construir epidemias de absurdo linguístico se nos esquecemos que tudo está diante dos nossos olhos. A significação é, desta maneira, dada em "fatos extraordinariamente gerais. Tais fatos não são quase nunca mencionados devido a sua grande generalidade." (§ 143, WITTGENSTEIN, 1979, p. 63)

Percebe-se que a essência é transferida da metafísica para o "solo áspero" do cotidiano (§ 371, WITTGENSTEIN, 1979, p. 120). O filósofo de Viena nos demonstra que a filosofia não analisa um fenômeno, como o pensar, mas um conceito, ou seja, seu "emprego" (§ 383, WITTGENSTEIN, 1979, p. 122). Será o emprego que dará vida ao signo, confundindo-se, pois, com suas margens de significância - "Todo signo sozinho parece morto. O que lhe dá vida? - No uso, ele vive" (§ 432, WITTGENSTEIN, 1979, p. 131). Nosso processo de aprendizagem é, antes, um processo de atuação, menos de recepção. Não aprendemos o conceito de dor por conta de um corte que tivemos nas mãos - muita das vezes, não estamos a sentir dor, mas aprendemos a jogar o jogo de que existe dor nos momentos em que cortamos a mão. Ou seja, aprendemos "o conceito de dor com a linguagem." (§ 384, WITTGENSTEIN, 1979, p. 122)

O itinerário do método wittgensteiniano na direção do "solo áspero" nos permite, pois, reencontrar o que abordamos como uma epistemologia histórica no contexto da formação do pensamento informacional, reestabelecendo um diálogo entre filosofia e epistemologia, epistemologia e teorias, dentro do campo, recontextualizando e reaproximando os cenários de produção conceitual, teórica e metodológica. Tratase, pois, de um método que nos coloca diante dos potenciais de aprofundamento, em CI, das relações entre as formações conceituais (no plano filosófico), as demarcações de uma teoria do conhecimento (no plano epistemológico) e as operacionalizações (no plano teórico) das dimensões socioaplicadas do campo, chegando até uma teoria geral da organização do conhecimento - aqui podemos encontrar diferentes aplicações deste métodofilosófico, agora tomado como método empírico, como no trabalho de Novellino (1996, 1998), Frohmann (1990) e Hajibayova e Buente (2017).

Especificamente, no plano sociossimbólico, o método wittgensteinano nos recoloca diante de uma dimensão ampla e aberta para a crítica da cultura: sua visão "gramatical", sustentada pela linguagem, funda um modo de perceber a dinâmica das diferenças e suas identidades na realidade social, demandado o olhar permanente sobre as contingências e suas singularidades. Trata-se, pois, em última instância, de um método cultural para a filosofia da informação tecida a partir dos olhares da CI.

\section{CONSIDERAÇÕES FINAIS: a vivência das gramáticas ordinárias}

\author{
"When Wittgenstein says that following \\ a rule is a practice, a technique, or \\ a custom, he emphasises that the \\ criteria of following a rule are public." \\ (FROHMANN, 1990, p. 91) \\ "Lutamos com a linguagem. \\ Estamos envolvidos numa luta com a \\ linguagem." \\ (WITTGENSTEIN, 1980, p. 27)
}

No decurso da construção do método wittgensteiniano, acompanhamos, pois, a substituição da "representabilidade" - que verificaremos nas gramáticas especulativas - por uma "apresentabilidade" (GIANNOTI, 1995) que identificaremos como gramáticas ordinárias - daquilo que se pode compreender. Partindo desta apresentação panorâmica, "um caminho mais seguro" pode vir a levar "a um emprego mais amplo" de nossos conceitos". Ao invés de permitir que uma linguagem, procurada fora do mundo - fora do mundo sensível e/ou fora do mundo da nossa linguagem -, se imponha a nós, e "não sirva para nada", como demonstra o aforismo 397, podemos procurar em nossa linguagem o quadro de referência para construir nossos destinos (§ 397, WITTGENSTEIN, 1979, p. 124). Posto que "a linguagem é um instrumento", também "seus conceitos são instrumentos" (§ 569, WITTGENSTEIN, 1979, p. 152).

Estas são as ferramentas para conceber o desenvolvimento de um indivíduo, de 
um grupo, de uma comunidade, inclusive de uma comunidade científica. São elas que nos levam a construir as ideias, a aprová-las como conceitos, a configurá-las como temas de pesquisa, a transformá-las em disciplinas e grupos de trabalho, a desenvolvê-las como uma especialidade, a ampliá-las como ciência - "conceitos nos levam a investigações. São a expressão do nosso interesse e o dirigem". (§ 570, WITTGENSTEIN, 1979, p. 152)

É preciso, por fim, concluir que há uma diferença na apresentação panorâmica diante da gramática que rege nossas visões. Em $\S$ 664, o filósofo de Viena apresenta dois tipos de gramática, a superficial e a profunda. A primeira é importante preocupação dos linguistas (WITTGENSTEIN, 1979). A segunda representa parte do método filosófico desenvolvido e aplicado à construção do pensamento wittgensteiniano em seu segundo momento. A própria noção de "gramática" aparece no bojo da gestação de um saber retórico e de um saber filológico, como também de um saber bibliológico - integrando-se aos pressupostos filosóficos que concebem o próprio campo, como é discutido em Capurro (1992).
Este princípio normativo da gramática, porém, aberto, estará presente na descrição conceitual da "gramática" de Wittgenstein. Aproximam-se, aqui, significados estruturais do conceito de gramática, resumidos na busca por uma "racionalidade". No entanto, o horizonte wittgensteiniano é inovador, na medida em que postula a existência de poligramáticas, determinadas apenas por topografias de uso. "Aquilo que se impregna diretamente em nós, pelo uso de uma palavra, é o seu modo de emprego na construção da frase; a parte do seu uso - poderíamos dizer - que se pode apreender com o ouvido" (§ 664, WITTGENSTEIN, 1979, p. 169).

A gramática profunda, ao contrário do que pode parecer, não está em um mundo extrassensível, mas na própria sensibilidade do mundo, cuja pele é a linguagem. Tocar alguém ou uma comunidade é se integrar ao uso de sua língua. Tocar o rio de qualquer realidade é vivenciar/sentir seus significados na ação - no uso, no jogo, que imprime vida aos seus conceitos. E esta vida é a própria aprendizagem em sua primitividade aberta.

Artigo recebido em $31 / 01 / 2018$ e aceito para publicação em 06/08/20I8

\section{A METHOD BETWEEN INFORMATION PHILOSOPHY AND KNOWLEDGE ORGANIZATION: Wittgenstein, historical epistemology and critics of language}

ABSTRACT From the conceptual-methodological path of Wittgenstein, the present philosophical reflection discusses the construction of a philosophical method, in the context of the philosophy of ordinary language, indicating its main concepts and approaches. The concepts of grammar, ordinary language, language games and panoramic presentation are discussed as the basis for a relationship between "remembering" and "philosophizing." For the study, the classic sources, in their translation to Portuguese, Logico-Philosophical and Philosophical Investigations, with the comparison of the Portuguese and Brazilian translations, as well as complementary sources, with different commentators, which indicate the changes in the profile of the thinking of a "first" to a "second" Wittgenstein. For the conceptual revision, we adopted the lexical exploration performed by Glock. We believe that the reflection contributes to the understanding of the depth of epistemological thinking of the Viennese philosopher. In the same way, the proposal, we project, allows revisiting Wittgenstein's conceptuality to the search for a correlation between concept and method, allowing us to "see" the philosopher in his (reflexive) act of creation. We believe that reflection contributes to the understanding of the depth of epistemological thinking of the Viennese philosopher and allows revisiting Wittgenstein's conceptuality to the search for a correlation between concept and method, leading us to "see" the philosopher in his (reflexive) act of creation.

Keywords: Wittgenstein. Philosophical method. Ordinary Language. Philosophy of Language. Panoramic presentation. 


\section{REFERÊNCIAS}

ALMEIDA, J. J. R. L. O Método entre o livro e o álbum. In: COLÓQUIO NACIONAL 5.; COLÓQUIO INTERNACIONAL WITTGENSTEIN, 2., 2008, Campinas. Anais... Campinas: Unicamp, Instituto de Filosofia e Ciências Humanas, 2008.

BLAIR, D. C. Information retrieval and the philosophy of language. The Computer Journal, v. 35, n. 3, p. 200-2007, 1992.

Information retrieval and the philosophy of language. Annual Review of Information Science and Technology (ARIST), v. 37, 2003.

CAPURRO, R. Epistemología y ciencia de la información. In: ENCONTRO NACIONAL DE PESQUISA EM CIÊNCIA DA INFORMAÇÃO, 5., 2003, Belo Horizonte. Anais... Belo Horizonte: Escola de Ciência da Informação da UFMG, 2003.

What is Information Science for? a philosophical reflection In: VAKKARI, P.; CRONIN, B. (Ed.). Conceptions of Library and Information Science; historical, empirical and theoretical perspectives. In: INTERNATIONAL CONFERENCE FOR THE CELEBRATION OF 20TH ANNIVERSARY OF THE DEPARTMENT OF INFORMATION STUDIES, UNIVERSITY OF TAMPERE, FINLAND.1991. Proceedings... London, Los Angeles: TaylorGraham,1992. p. 8296.

CONDÉ, M. L. L. Wittgenstein: linguagem e mundo. São Paulo: Annablume, 1998.

As Teias da razão: Wittgenstein e a crise da racionalidade moderna. 2001. Tese (Doutorado em Filosofia) - Faculdade de Filosofia e Ciências Humanas, Universidade Federal de Minas Gerais, Belo Horizonte, 2001.

EDMONDS, D.; EIDINOW, J. O atiçador de Wittgenstein: a história de uma discussão de dez minutos entre dois grandes filósofos. Tradução de Pedro Jorgensen Jr. Rio de Janeiro: Difel, 2003.
FROHMANN, B. Revisiting "what is a document?" Journal of documentation, v. 65, n. 2, p. 291-303, 2009.

. Rules of indexing: a critique of mentalism in information retrieval theory. Journal of Documentation, v. 46, n. 2, jun. 1990.

GONZÁLEZ DE GÓMEZ, M. N. Comentários ao artigo "Hacia um nuevo pardigma em bibliotecologia". Transinformação, Campinas, v. 8, n. 3, p. 44-56, set./dez. 1996.

GIANNOTI, J. A. Apresentação do mundo: considerações sobre o pensamento de Ludwig Wittgenstein. São Paulo: Cia das Letras, 1995.

GLOCK, H-J. Dicionário Wittgenstein. Rio de Janeiro: Jorge Zahar, 1998.

GRACIOSO, L. S.; SALDANHA, G. S. Ciência da Informação e Filosofia da Linguagem: da pragmática informacional à web pragmática. Araraquara - SP : Junqueira \& Marin, 2011.

HAJIBAYOVA, L.; BUENTE, W. Representation of indigenous cultures: considering the Hawaiian hula. Journal of Documentation, v. 73, n. 6, p. 1137-1148, 2017.

HALLER, R. Wittgenstein e a filosofia austríaca: questões. Tradução Norberto de Abreu e Silva Neto. São Paulo: ed. USP, 1990.

HJORLAND, Birger. Empiricism, rationalism and positivism in library and information science. Journal of Documentation, Londres, v. 61, n. 1, p. 130-152, 2005.

JANIK, A.; TOUMIN, S. A Viena de Wittgenstein. Tradução Álvaro Cabral. Rio de Janeiro: Campus, 1991.

LUCKHARDT, C. G. Philosophy in the big typescript. Synthese, v. 87, p. 255-272, 1991.

MONK, R. Wittgenstein: o dever do gênio. Tradução Carlos Afonso Malferrari. São Paulo: Cia das Letras, 1995. 
MORENO, Arley. Wittgenstein: os labirintos da linguagem. São Paulo: Moderna, 2000.

NOVELLINO, M. S. F. A teoria da ação comunicativa e a representação da informação. Informare: caderno do programa de pósgraduação em ciência da informação, Rio de Janeiro, v. 2, n. 2, p. 73-79, jul./ dez. 1996.

A linguagem como meio de representação ou de comunicação da informação. Perspect. Cienc. Inf., Belo Horizonte, v. 3, n. 2, p. 137-146, jul./dez. 1998.

SALDANHA, G. S. Entre o silêncio e o alarido: Wittgenstein na Ciência da Informação In: Temas de pesquisa em Ciência da Informação no Brasil.1 ed.São Paulo : Escola de Comunicação e Arte da Universidade de São Paulo, 2010, v.1, p. 65-84.

TUGENDHAT, E. Wittgenstein I: a impossibilidade de uma linguagem privada.
Novos Estudos CEBRAP, São Paulo, n. 32, p. 4763, mar. 1992.

WITTGENSTEIN, L. Culture and value. Oxford: Blackweall, 1980.

Da certeza. Lisboa: ed. 70, 1990.

Investigações Filosóficas. São Paulo: Abril Cultural, 1979.

O Livro azul. Lisboa: Ed.70, 1992a.

Edições 70, 1992b.

Loyola, 2005.

Observações filosóficas. São Paulo:

Tractatus logico-philosophicus. São

Paulo: Ed. Nacional; Edusp, 1968.

Tratado Lógico Filosófico: investigações filosóficas. 3. ed. Lisboa: Fundação Calouste Gulbenkian, 2002. 